\title{
COLLATERALIZED DEBT OBLIGATIONS' VALUATION USING THE ONE FACTOR GAUSSIAN COPULA MODEL
}

\author{
Petra Buzková, Petr Teplý*
}

\begin{abstract}
:
The aim of this paper is to shed light on Collateralized Debt Obligation (CDO) valuation based on data before and during the 2007-2009 global turmoil. We present the One Factor Gaussian Copula Model and examine five hypotheses regarding CDO sensitivity to entry parameters. For our modelling we used data of the CDX NA IG 5Y V3 index from 20 September 2007 until 27 February 2009 and we appropriately transform its quotes into CDO quotes. Based on the results we discovered four main deficiencies of the CDO market: i) an insufficient analysis of underlying assets by both investors and rating agencies; ii) investment decisions arise from the valuation model based on expected cash flows, they neglected other factors such as mark-tomarket losses; iii) mispriced correlation; and finally iv) obligation of the mark-to-market valuation. Based on the mentioned recommendations we conclude that the CDO market has a chance to be regenerated but in smaller volumes compared to the pre-crisis period. However, it would then be more conscious, driven by smarter motives rather than by pure arbitrage and profit incentives.
\end{abstract}

Keywords: Collateralized Debt Obligations, Copula Function, valuation, securitization, One Factor Gaussian Copula Model

JEL Classification: G01, G15, G17, C63

\section{Introduction}

By 2007, mounting defaults in the US sub-prime mortgage market led to US market instability, unleashing a global financial contagion that spread around the world, roiling markets and causing world economic upheaval. This contagion led to, for example, the nationalization of big financial institutions, bank failures, the end of an era in investment banking, increased federal insurance on banking deposits, government bailouts and opportunistic investments by sovereign wealth funds (Teplý, 2010). Consequently, the world credit markets stalled significantly and raised the doubts of

* Faculty of Social Science, Institute of Economic Studies, Charles University in Prague (teply@fsv. cuni.cz; benesova_p@seznam.cz). Financial support from The Grant Agency of Charles University (Project GAUK 114109/2009 - Alternative Approaches to Valuation of Credit Debt Obligations), The Czech Science Foundation (Projects GACR 403/10/P278 - The Implications of The Global Crisis on Economic Capital Management of Financial Institutions and GACR P403/10/1235 - The Institutional Responses to Financial Market Failures), The Research Institutional Framework Task IES (Project MSM0021620841- Integration of The Czech Economy into The European Union and its Development) is gratefully acknowledged. 
market participants and policymakers about the proper and fair valuation of financial derivatives and structured products such as collateralized debt obligations (CDOs).

The aim of the paper is to contribute to the understanding of CDOs and shed light on $\mathrm{CDO}$ valuation based on data before and during the current financial upheaval. Since CDOs rank among the more advanced structured products, the models used for their valuation are very complex and therefore investors often relied on assessment of rating agencies without a proper understanding of the model. After explaining the valuation model in the context of the pending turmoil, we will be able to specify and demonstrate recent weaknesses of the $\mathrm{CDO}$ market and provide recommendations for the future existence and regulation of $\mathrm{CDO}$ markets.

This paper is organized as follows: after a brief introduction, we describe basic principles of CDOs. In the third section we present the One Factor Gaussian Copula Model. Although it is a relatively simple model, it suitably illustrates the main sensitivities and key features of CDO valuation. Moreover, it is better understandable. The fourth section develops the theoretical concept presented in the third section. In the fifth section, we examine five hypotheses. Based on the outcomes, we detect main flaws of the CDO valuation and make relevant recommendations that should help to restore confidence of the $\mathrm{CDO}$ market. Finally, in conclusion we summarize the paper and state final remarks.

\section{Basic Principles of CDOs}

\subsection{CDO basics}

IMF (2008) offers the following definition of a CDO: "A structured credit security backed by a pool of securities, loans, or credit default swaps, where securitized interests in the security are divided into tranches with differing repayment and interest earning streams." A CDO is a contract between an originator and an investor with specified maturity in which the originator commits to pay the investor regular premium payment until maturity. The investor in exchange promises to bear all the credit risk. In case of no default until maturity an originator continues to regularly pay the investor the premium. In case of default the investor compensates the originator the loss the originator suffered.

Moreover, CDO represents a product with a diverse risk structure. Through tranching it offers the investor to choose the amount of credit risk he would absorb based on his risk profile and appetite. The basic principle in a simplified form is sketched in the scheme below. An illustrative CDO is divided into four tranches each absorbing a portion of the resulting cash flows or default impact; the first tranche holder compensates the issuer for the first $5 \%$ of defaults and the remainder flows are compensated by more senior tranches. 
Figure 1

\section{Basic Structure of a CDO}

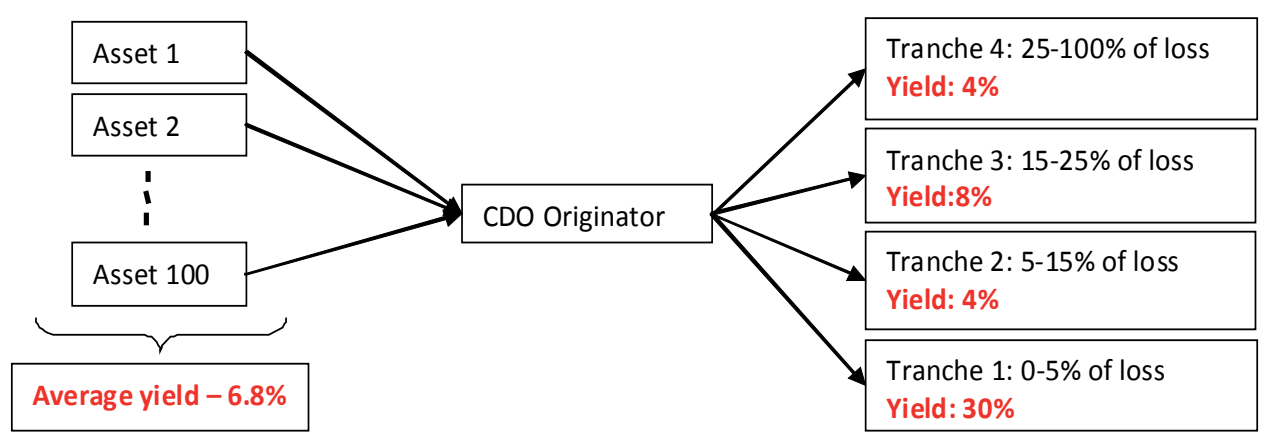

Source: Authors' calculations

The paper analyses synthetic CDOs not only because it markedly outweighs cash $\mathrm{CDO}$ in terms of volume but also its valuation is less complex. Synthetic CDO is an unfunded $\mathrm{CDO}$ where the underlying assets are not factually owned by an originator but they are acquired by selling CDS to chosen assets. The motive for a synthetic CDO originator is thus not a credit risk transfer but profit or capital relief. For more details about various types of CDOs see Fabozzi et al. (2008), Fabozzi and Kothari (2008) or Mejstř́k et al. (2008).

\subsection{CDO indices}

CDOs rank equivalent to an over the counter (OTC) products and hence no official exchange exists. CDO indices were established during times of high CDO trade volume to achieve standardization in CDO trading. In our analysis we use the CDX index data. There are several advantages of using the CDX index compared to a single CDO for reasons, such as diversification, transparency, or standardization. The main reason is its liquidity, i.e. reliable market quotes. Figure 2 shows an evolution of the CDX IG 5Y index Series 3 index since 2004 and clearly reveals main events on credit markets in the year 2008: Bear Stearns' bankruptcy in March 2008 and Lehman Brothers' collapse in September 2008 definitely confirming serious troubles financial world went into. 
Figure 2

CDX IG 5Y Index Series 3 (September 2004 - February 2009)

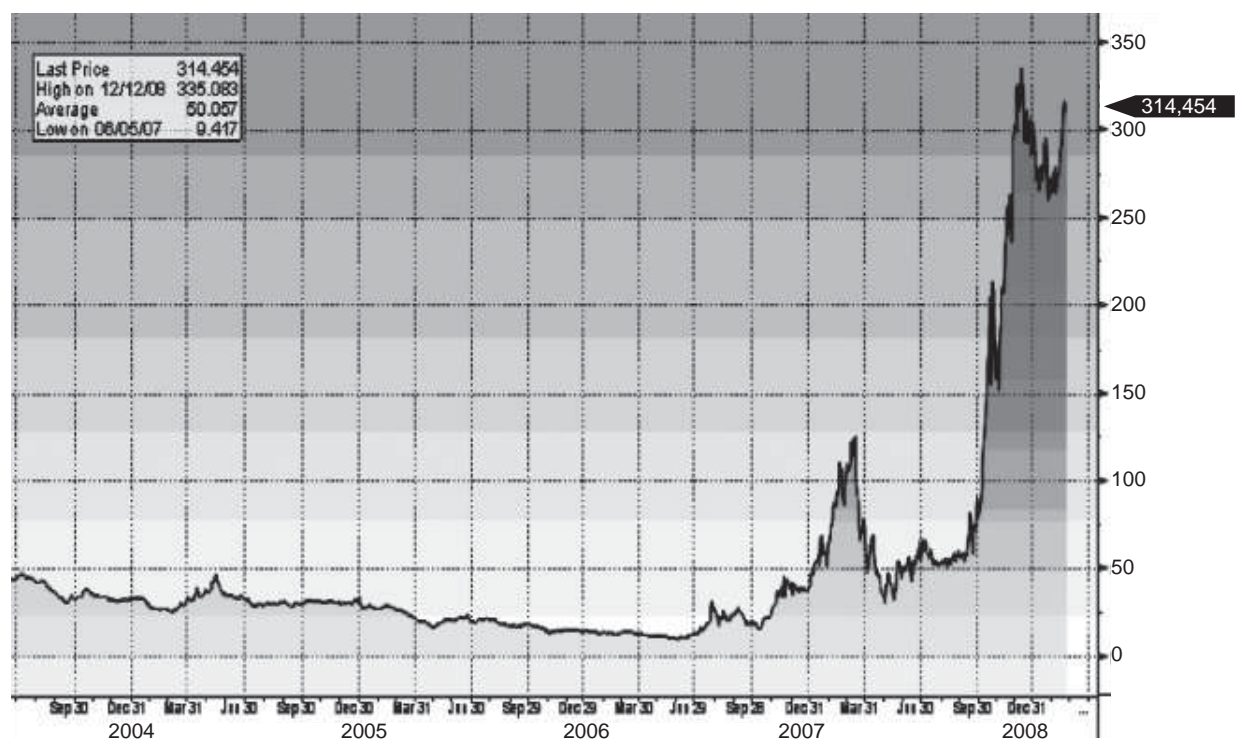

Source: Bloomberg

\subsection{CDO risks}

CDO bears many risks for the investor, such as interest rate risk, cross-currency risk, ramp-up risk and reinvestment risk (Fabozzi and Kothari, 2008); we will focus on the following two: i) correlation risk and ii) counterparty risk. By a correlation we mean the correlation between the defaults of underlying assets of a CDO. The higher the correlation the more fragile is the whole CDO structure. The importance of a correlation differs for different tranches' investors. Correlation also changes over time and depends on macroeconomic conditions. In times of a recession the correlation between assets tends to increase, whereas it is low in times of growth (Kakodkar et al., 2003). This is a very important feature which is essential to understand when investing in a CDO. Correlation will be discussed in more details in the following sections.

A CDO investor is subject to a counterparty risk of both a CDO issuer and all underlying assets' issuers. Usually, each CDO tranche is classified by a rating. This rating, however, can theoretically be reviewed and changed by a rating agency at any time. In previous years the rating agencies' assessment of risk was taken as gospel by all its users and they acted as if the rating was once given and irreversible. In fact, a default of one underlying asset can cause a downgrade of all tranches of a CDO. Consequently, not only a junior tranche investor is hit by the default but also a senior tranche investor suffers a loss - a mark-to-market loss - as the spread of the senior tranche soars. The threat of a downgrade of an asset and all its consequences based on numerical evidence will be further discussed in the fifth section. 
Figure 3 illustrates the above explained risks and their consequences. A right $\mathrm{x}$-axis of the figure depicts institutions that issued more than USD 10 billion nominal value of CDOs in the most successful year 2006. The left x-axis shows the writedowns of the institutions since mid 2007 until February 2009. Citigroup with nearly USD 60 billion of writedowns was on the first place followed by Merrill Lynch and UBS. These writedowns have their roots in a high volume of subprime mortgages offered recklessly to households with a low credibility in the US. The mortgages were securitized into a mortgage backed securities (MBS) and then sold to institutional investors. In this way the credit risk of the mortgages was spread to the whole financial sector. After some mortgage defaults, many institutions involved in this process were hit and some of them even defaulted (such as Lehman Brothers or US mortgage agencies Fannie Mae and Freddie Mac).

These involvements triggered a spiral of losses and downgrades exacerbated by diminishing liquidity: first settlements of CDO contracts, downgrades of MBS holders, consecutive downgrades of CDO holders and massive writedowns of many counterparties included in MBS or CDO business. This also resulted in CDS spreads widening and further mark-to-market losses. Some CDOs had to be terminated before maturity creating even higher losses. As a result of high interdependence within a financial sector and its strong link to all business sectors, a series of problems of underlying companies led to a serious financial crisis.

Figure 3

Top CDO Issuers and their Writedowns as of February 2009 (in USD billions)
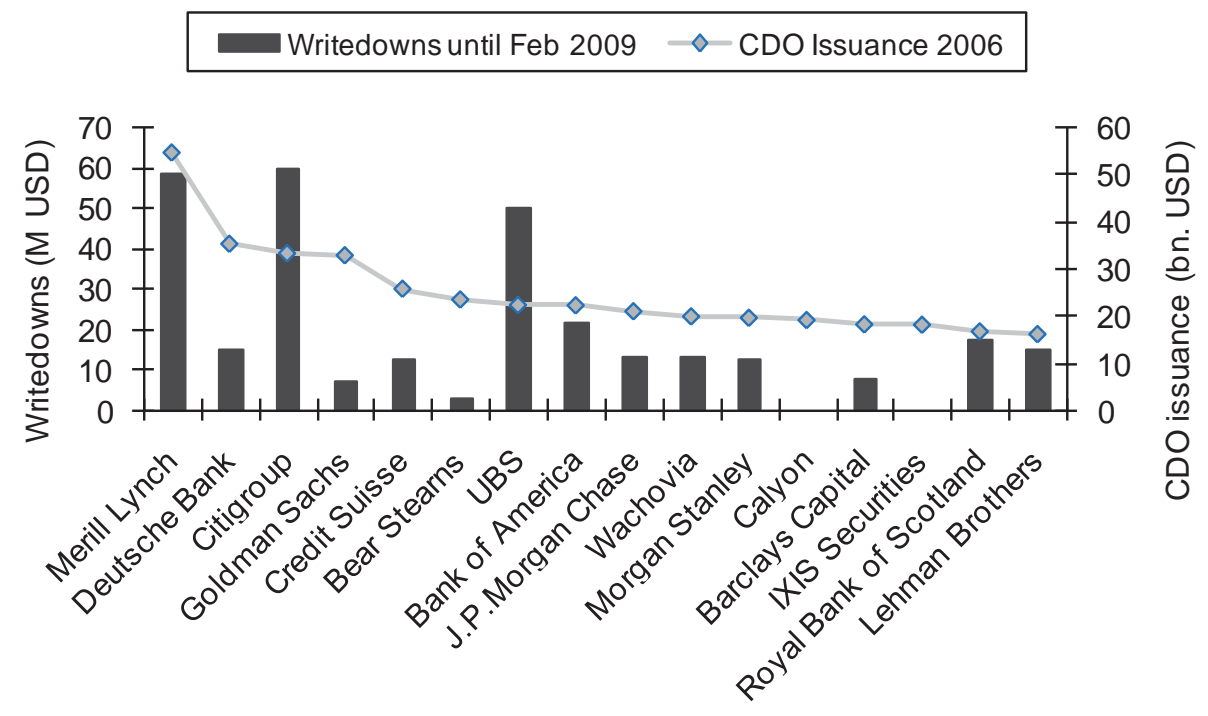

Source: Authors' calculations based on www.abalert.com 


\subsection{CDO issuance}

Although CDOs were first presented in the 1980s, their issuance registered an outstanding growth since 2001 when most CDOs received a rating as the rating agencies became more familiar with CDOs (Fabozzi et al., 2008). In 2004, the worldwide CDO issuance amounted to USD 157 billion and peaked in 2006 when totalled USD 521 billion. As a result of the financial turmoil, the CDO issuance plummeted to mere USD 62 billion in 2008 (as of the end of 2008, total CDO outstanding amounted to USD 870 billion) and to mere USD 4.3 billion in 2009. On the other hand, in the year of 2010 the CDO issuance saw a year-on-year jump by $85 \%$ to USD 8.0 billion.

The high growth in CDO activity in 2005 and 2006 was mainly due to arbitrage activity (i.e. profit motives) that replaced credit risk elimination (the initial motive of CDO issuance). The highest tranches often obtained the highest possible score from rating agencies and therefore were wrongly considered a safe investment. However, as a result of the US mortgage crisis in 2007, the issuance of CDOs fell dramatically and the premiums the issuers were willing to pay for credit protection skyrocketed. As of October 2008 the CDO market was frozen and 67\% of the CDOs issued since late 2005 to middle 2007 were in formal state of default (Thomson Reuters, 2008). Many institutional investors suffered massive write-downs (e.g. Citigroup, UBS or KBC), many of them were bailed-out (e.g. AIG, Royal Bank of Scotland or Northern Rock), while some were acquired by a stronger competitor (e.g. Bear Stearns, Merrill Lynch or Washington Mutual).

\section{The One Factor Gaussian Copula Model}

The One Factor Gaussian Copula Model is a basic model of a CDO. Its basic form based on a principle of correlation of default times firstly introduced by Li (2000). The main idea behind all CDO valuation models lies in determining such premium of a tranche that ensures the present value of premium payments equal to the present value of the loss payments implying that the total present value of the contract is zero. Both the loss payment and the premium payment depend on a number of defaults in the future and their timing, which further determines a time distribution of loss. As none of this is known, losses are random variables whose expected value should be computed within the model. First, we should determine the probability of default of an obligor by time $t$. Then, having this distribution for each obligor and combining it with a correlation structure among the obligors, we identify the joint distribution function. The factor model solves the problem with a correlation structure between obligors. The copula function approach introduces a quantitative way how to cope with multidimensional distribution functions. After obtaining the joint distribution, it is straightforward to deduce the probability of number of defaults in each time period and the loss distribution.

The model can be extended either by using multiple factors instead of one (Hull and White, 2004) by assuming other than normal distribution of default times (Gregory and Laurent, 2004) or by modifying assumptions of entry parameters such as recovery rate or correlation (Wang, et al., 2006). General theory of copulas can be found in 
Nelsen (2006), upgraded copulas theory and transformation of copulas is studied by Hájek and Mesiar (2008), Klement et al. (2005) or in Kybernetika (2008).

Suppose a CDO with $n$ underlying assets and denote $i$ an underlying asset, $i=1, \ldots, n$. Using One Factor Gaussian Copula Model our task is to set the premium payment $V$ for each tranche so that the present value of premium payments equals to the present value of loss payments. Such premium $V^{*}$ satisfies:

$$
V^{*}=\frac{\sum_{k=1}^{T} B\left(t_{0}, t_{k}\right)\left[E L_{\left(K_{A}, K_{D}\right)}\left(t_{k}\right)-E L_{\left(K_{A}, K_{D}\right)}\left(t_{k-1}\right)\right]}{\sum_{k=1}^{T} B\left(t_{0}, t_{k}\right)\left(t_{k}-t_{k-1}\right)\left[1-E L_{\left(K_{A}, K_{D}\right)}\left(t_{k}\right)\right]}
$$

where $B\left(t_{0}, t_{k}\right)$ is a discount factor discounting from time $t_{k}, k=1, \ldots, T$ to $t_{0}$ (, thus $B\left(t_{0}, t_{k}\right)=\exp \left(-\int_{0}^{k} f(0, s) d s\right)$, where $f(0, s)$ is a spot forward interest rate.

To determine optimal premium $V^{*}$ we need the expected loss function $E L_{\left(K_{A}, K_{D}\right)}\left(t_{k}\right)$ which is given by equation (2):

$$
E L_{\left(K_{A}, K_{D}\right)}\left(t_{k}\right)=\frac{1}{K_{D}-K_{A}} \sum_{j=1}^{n}\left[\min \left(\frac{L_{j}\left(t_{k}\right)}{A \cdot n} ; K_{D}\right)-K_{A}\right]^{+} \cdot P\left(N\left(t_{k}\right)=j\right)
$$

$K_{A}$ and $K_{D}$ define tranches, i.e. an attachment resp. detachment point of a tranche expressed in percentage. We suppose the same volume of each underlying asset in the CDO pool and denote it $A . L_{j}\left(t_{k}\right)$ is a cumulative loss on the whole portfolio by time $t_{k}$ given $j$ defaults. To put it simply, to reach $E L_{\left(K_{A}, K_{D}\right)}\left(t_{k}\right)$ we count loss on a tranche for all cases of $j=0,1, \ldots, n$ defaults $\left[\min \left(\frac{L_{j}\left(t_{k}\right)}{A-n} ; K_{D}\right)-K_{A}\right]^{+}$and sum them weighted by their probability. As other parameters of equation (2) are known, only the probability of $j$ defaults by time $t_{k}$, i.e. $P\left(N\left(t_{k}\right)=j\right.$ is to be determined.

Therefore a random variable $\tau_{i}$ is introduced denoting a default time of $i$-th underlying asset, $i=1, \ldots, n$. It is essential for our calculation to deduce its properties.

The derivation is not straightforward; we divide it in two steps. In the first step we condition the probability on one factor $M$ which is supposed to be normally distributed:

$$
X_{i}=\rho_{i} M+\sqrt{1-\rho_{i}^{2}} \cdot \varepsilon_{i}
$$

where $\varepsilon_{i}$ is a random variable with standard normal distribution, $i=1, \ldots, n$. In One factor model $\varepsilon_{i}$ and $M$ are independent. Therefore also $X_{i}$ is a random variable with normal distribution. $\rho_{i}$ is a constant called loading factor, $\left|\rho_{i}\right|<1$. Based on copula approach there is a link between $X_{i}$ and $\tau_{i}$. For a fixed $i$ suppose $\Phi(x)$ is a distribution function of $X_{i}$ and $F_{i}(t)$ is a distribution function of $\tau_{i}$. If $F_{i}$ is increasing, then there exists bilaterally unique correspondence between $t \in D_{F_{i}}$ and $x \in D_{\Phi}$ such that:

$$
F_{i}(t)=P\left(\tau_{i} \leq t\right)=P\left(X_{i} \leq x\right)=\Phi(x) \text { or }
$$




$$
t=F_{i}^{-1}(\Phi(x)) \quad \text { resp. } x=\Phi^{-1}\left(F_{i}(t)\right)
$$

i.e. $X_{i} \mathrm{~s}$ are mapped to $\tau_{i}$ using a percentile-to-percentile transformation.

From now on we suppose a homogenous portfolio - i.e. the default times of all obligors have the same distribution $-\tau_{i}=\tau$ for all $i=1, \ldots, n$ and correlation among the default times is the same for each pair of obligors. That implies that also the loading factor is the same $-\rho_{i}=\rho$ for all $i=1, \ldots, n$. The number of defaults at time $t$ denoted $N(t)$ follows a binomial distribution, therefore:

$$
P(N(t)=j \mid M=m)=\left(\begin{array}{c}
n \\
j
\end{array}\right) \cdot p j(\tau \leq t \mid M=m) \cdot(1-P(\tau \leq t \mid M=m))^{n-j}
$$

where $P(\tau \leq t \mid M=m)$ is derived from equation (6) using One Factor Gaussian Copula approach.

$$
P(\tau \leq t \mid M=m)=\Phi\left(\frac{\phi^{-1}(F(t)-\rho \cdot m)}{\sqrt{1-\rho^{2}}}\right)
$$

The reason for conditioning in the first step is that based on the theory of copulas, the default times of obligors are mutually independent only conditionally on a factor value. Only having independent default times the binomial distribution in equation (5) can be used.

In the second step using integral over $M$ we derive the unconditional probability:

$$
P(N(t)=j)=\int_{-\infty}^{\infty}\left(\begin{array}{l}
n \\
j
\end{array}\right) \cdot\left(\Phi\left(\frac{\Phi^{-1}(F(t)-\rho \cdot m)}{\sqrt{1-\rho^{2}}}\right)\right)^{j} \cdot\left(1-\Phi\left(\frac{\Phi^{-1}(F(t)-\rho \cdot m)}{\sqrt{1-\rho^{2}}}\right)\right)^{n-1} \cdot \phi(m) d m
$$

Given the mathematical background, in the following section we will present some practical aspects of the valuation. Consequently parameters of the model will be chosen appropriately given recent improvements in CDO pricing. Finally, we will value the CDX index and its tranches before and during the financial crisis, implement comparative statistics and assess its sensitivity in context with the current financial crisis.

\section{Implementation of CDO Valuation}

In this section we will show how to implement the valuation of a CDO contract following the theoretical concept introduced in the previous part. All market data were taken from Bloomberg. To implement the valuation it is necessary to adopt some assumptions about the entry parameters. The main is the distribution of $\tau$ and pairwise correlation $\rho$.

One useful measure of probability distribution of $\tau$ is hazard rate function $h(t)$ defined in $\operatorname{Li}(1998)$ :

$$
h(t)=\frac{f(t)}{1-F(t)}
$$

where $F(t)$ is the distribution function of $\tau$ and is $f(t)$ the density of the default times. 
After some derivations we obtain:

$$
f(t)=h(t) \exp \left(-\int_{0}^{t} h(s) d s\right)
$$

We suppose that the hazard rate function is constant at some level called hazard rate and denoted by $\lambda$. Based on this assumption the density of the default time simplifies to an exponential one:

$$
f(t)=\lambda \cdot \exp (-\lambda t)
$$

Hazard rate of an asset is then deduced from the market quotes of credit default swap (CDS).

Concerning correlation, the correlation parameter is defined as a loading factor in the One Factor Model in equation (3). We suppose that correlation is the same for each pair of assets. There are two approaches to correlation determination: implied correlation and base correlation. In both approaches the correlation is determined endogenously. Implied correlation is defined as a correlation for which the net present value of a tranche equals zero. The base correlation approach is more complex. Suppose a CDX index with following tranching: $(0-3) \%,(3-7) \%,(7-10) \%,(10-15) \%$ and $(15-30) \%$. Now imagine a non-existing series of tranches $(0-7) \%,(0-10) \%,(0-15) \%$ and $(0-30) \%$. Implied correlation is a value of correlation that sets the non-existing tranches' values to zero.

Theoretically, the implied and base correlation should be the same for all tranches and subsets of tranches. The discussion of values of correlation in imperfect markets will follow. Generally, it is observed that it differs through tranches and even through time. For more discussion of correlation see Fabozzi and Kothari (2008) or Benešová and Teplý (2010).

\section{Results of the Model}

The aim of this section is to illustrate CDO pricing using the model presented in Section 3 based on assumptions taken in Section 4. We run the calculation introduced above to show market risk of a CDO and to model the mark-to-market loss of a holder of senior tranches (i.e. we demonstrate what were the consequences of massive and naïve investment in AAA rated tranches and why the CDO market nearly ceased to exist).

The section consists of three parts. At the beginning we briefly discuss the data used for our research. In the second part we determine a relation of each tranche's premium to correlation and hazard rate. We also analyze a loss after default and show the implications of three actual defaults on recent data. As we have examined data of an index instead of a CDO, we estimate how a real CDO would have behaved in two recent years, which were affected by the financial crisis. The last part deals with an overall assessment of the CDO market, its weaknesses and its role in the crisis and contribution to the crisis. The main flaws of the market are spotted and their correction is proposed. 


\subsection{Data used}

As we discussed above, the volume of CDO trades fell dramatically in 2008 after years of growth and the liquidity of the market disappeared. CDS index valuation will be implemented due to both difficulties to get market data and low level of liquidity of CDOs. We choose the most traded series of the main CDX index -9 and maturity 5 years (usually noted as CDX NA IG 5Y V3). This index originally counted 125 underlying bonds issued by North American companies. The effective date of the index was on 20 September 2007. Since then there have been 3 defaults of underlying companies (Federal Home Loan Mortgage Corporation, Federal National Mortgage Association and Washington Mutual). After each event of default a new version of the index had to be launched so that new index investors had a starting position with no defaults and continuity of the index was sustained. First two defaults were settled at once; therefore a third version of this index was trading at the time of the valuation.

\subsection{Examination of hypotheses}

We examine five hypotheses about the entry parameters. Hypotheses 1, 2 and 3 concern correlation within the $\mathrm{CDO}$ model, the Hypothesis 4 deals with hazard rate and Hypothesis 5 raises the issue of mark-to-market valuation.

\subsubsection{Correlation evaluation (Hypotheses 1, 2 and 3)}

\section{Hypothesis 1: The higher the asset correlation, the lower the risk premium for a junior tranche and the higher the risk premium for a senior tranche.}

A correlation parameter shows the correlation between each pair of underlying assets. Figure 5 shows the role of correlation in each tranche. We fixed the hazard rate at 0.07 and calculated the premium of a tranche for a varying level of correlation on vertical axis.

For the most junior tranche (0-3\%) the premium is a decreasing function of correlation whereas for the most senior tranche the premium increases with correlation (see Figure 4). The mezzanine tranches are less sensitive to correlation. Moreover, the relation between correlation and premium does not always have to be monotonic (see results for the $15-30 \%$ tranche). Higher correlation has a lower value for an investor buying protection on the equity tranche as he is willing to pay less to the protection buyer. The opposite holds for the senior tranche investor for whom higher correlation has a higher value. To conclude, the model confirms Hypothesis 1.

For proper CDO valuation we need to determine the level of correlation. First, we will use the implied correlation. See Table 1 for the results of the valuation based on different values of correlation. In the first row there are market quotes of CDX tranches on 28 February 2009. For the three lowest tranches the values displayed are already recalculated to the upfront payment quotes. Market quote of the tranche is also incorporated in Figure 5 by a grey line and its intersection point with the black line determines the implied correlation. 
Figure 4

Tranche Premium for a Given Level of Correlation (as of 28 February 2009)

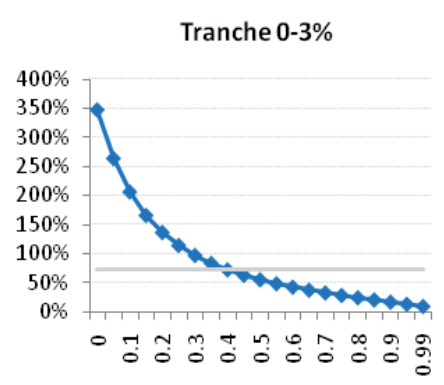

Tranche 7-10\%

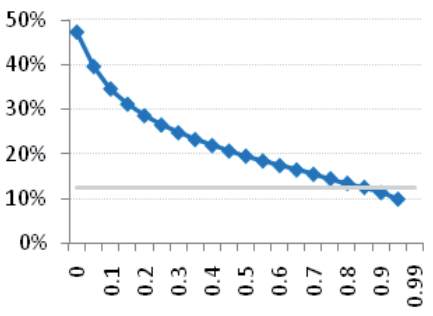

Tranche 15-30\%

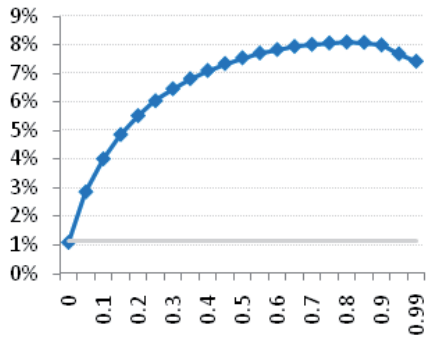

Tranche 3-7\%

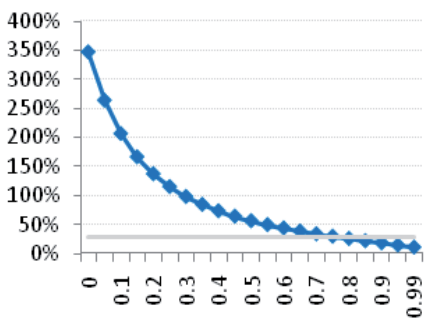

Tranche $10-15 \%$

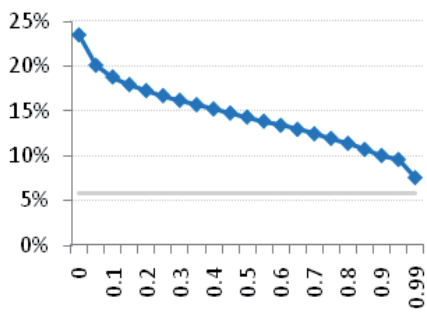

Tranche $30-100 \%$

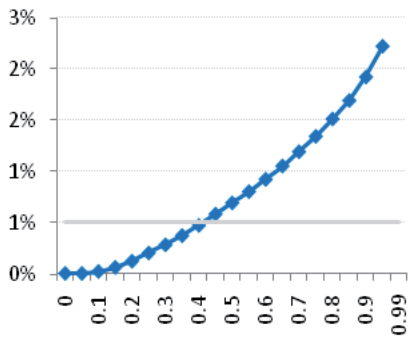

Source: Authors

Table 1 displays that the correlation differs substantially among tranches. The difference between implied correlations is a usual outcome of CDO valuation models (Hull and White, 2004, or Amato and Gyntelberg, 2005). This is sometimes called "correlation smile" and points to both imperfection of the model and the fact that market quotes comprise other factors that are not included in the model. Figure 6 compares implied correlation of tranches on 28 February 2009 and 20 September 2007 and demonstrates that implied correlation was more stable through tranches in September 2007. Therefore we conclude that distressed markets and inappropriate valuation of tranches caused current huge variations of implied correlation among tranches in February 2009. 
Figure 5

Implied Correlation of Tranches on 28 February 2009 and 20 September 2007

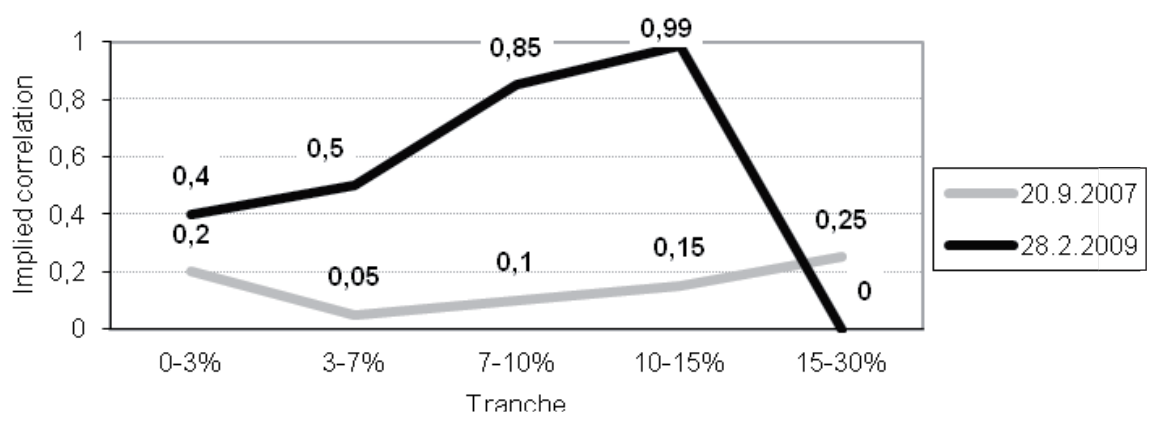

Source: Authors

Table 1

Results of Valuation on 28 February 2009 with Hazard Rate of 0.07

\begin{tabular}{|c|c|c|c|c|c|c|}
\hline & $\begin{array}{c}\text { Tranche } \\
0-3 \%\end{array}$ & $\begin{array}{c}\text { Tranche } \\
3-7 \%\end{array}$ & $\begin{array}{c}\text { Tranche } \\
7-10 \%\end{array}$ & $\begin{array}{c}\text { Tranche } \\
10-15 \%\end{array}$ & $\begin{array}{r}\text { Tranche } \\
15-30 \% \\
\end{array}$ & $\begin{array}{l}\text { Tranche } \\
30-100 \%\end{array}$ \\
\hline $\begin{array}{l}\text { Market } \\
28 / 2 / 2009\end{array}$ & $81.72 \%$ & $53.85 \%$ & $22.97 \%$ & $7.72 \%$ & $1.14 \%$ & $0.50 \%$ \\
\hline \multicolumn{7}{|l|}{ correlation } \\
\hline 0.00 & $98.02 \%$ & $92.86 \%$ & $86.68 \%$ & $23.45 \%$ & $1.08 \%$ & $0.00 \%$ \\
\hline 0.05 & $97.46 \%$ & $90.37 \%$ & $75.91 \%$ & $20.07 \%$ & $2.85 \%$ & $0.00 \%$ \\
\hline 0.10 & $96.59 \%$ & $85.87 \%$ & $67.40 \%$ & $18.76 \%$ & $4.00 \%$ & $2.00 \%$ \\
\hline 0.15 & $95.21 \%$ & $80.89 \%$ & $61.18 \%$ & $17.91 \%$ & $4.85 \%$ & $0.06 \%$ \\
\hline 0.20 & $93.28 \%$ & $76.01 \%$ & $56.34 \%$ & $17.24 \%$ & $5.51 \%$ & $0.12 \%$ \\
\hline 0.25 & $90.88 \%$ & $71.39 \%$ & $52.34 \%$ & $16.67 \%$ & $6.03 \%$ & $0.20 \%$ \\
\hline 0.30 & $88.08 \%$ & $67.03 \%$ & $44.91 \%$ & $16.15 \%$ & $6.45 \%$ & $0.28 \%$ \\
\hline 0.35 & $84.95 \%$ & $62.98 \%$ & $45.88 \%$ & $15.66 \%$ & $6.80 \%$ & $0.37 \%$ \\
\hline 0.40 & $81.54 \%$ & $59.12 \%$ & $43.12 \%$ & $15.19 \%$ & $7.09 \%$ & $0.47 \%$ \\
\hline 0.45 & $77.87 \%$ & $55.44 \%$ & $40.56 \%$ & $14.73 \%$ & $7.33 \%$ & $0.58 \%$ \\
\hline 0.50 & $73.98 \%$ & $51.89 \%$ & $38.15 \%$ & $14.28 \%$ & $7.53 \%$ & $0.69 \%$ \\
\hline 0.55 & $69.87 \%$ & $48.45 \%$ & $35.84 \%$ & $13.82 \%$ & $7.70 \%$ & $0.80 \%$ \\
\hline 0.60 & $65.53 \%$ & $45.07 \%$ & $33.59 \%$ & $13.36 \%$ & $7.82 \%$ & $0.92 \%$ \\
\hline 0.65 & $60.97 \%$ & $41.72 \%$ & $31.36 \%$ & $12.90 \%$ & $7.93 \%$ & $1.05 \%$ \\
\hline 0.70 & $56.15 \%$ & $38.36 \%$ & $29.13 \%$ & $12.41 \%$ & $8.00 \%$ & $1.19 \%$ \\
\hline 0.75 & $51.02 \%$ & $34.94 \%$ & $26.79 \%$ & $11.90 \%$ & $8.05 \%$ & $1.34 \%$ \\
\hline 0.80 & $45.52 \%$ & $31.40 \%$ & $24.34 \%$ & $11.34 \%$ & $8.08 \%$ & $1.51 \%$ \\
\hline 0.85 & $39.46 \%$ & $27.51 \%$ & $22.10 \%$ & $10.66 \%$ & $8.07 \%$ & $1.69 \%$ \\
\hline 0.90 & $32.68 \%$ & $22.44 \%$ & $18.82 \%$ & $9.99 \%$ & $7.98 \%$ & $1.92 \%$ \\
\hline 0.95 & $24.52 \%$ & $17.62 \%$ & $15.12 \%$ & $9.54 \%$ & $7.67 \%$ & $2.22 \%$ \\
\hline 0.99 & $15.30 \%$ & $12.67 \%$ & $8.71 \%$ & $7.51 \%$ & $7.41 \%$ & $2.64 \%$ \\
\hline $\begin{array}{l}\text { Implied } \\
\text { correlation }\end{array}$ & 0.40 & 0.50 & 0.85 & 0.99 & 0.00 & 0.40 \\
\hline
\end{tabular}

Source: Authors 


\section{Hypothesis 2: Base correlation is more stable measure of correlation than implied correlation.}

As Figure 7 depicts, base correlation recorded less variance than the implied correlation as of 28 February 2009. To illustrate this, suppose an investment in all tranches of a CDO totaling USD 1 million. The distribution of the notional among tranches is given by their attachment and detachment points (e.g. we invest USD 30,000 in equity tranche, USD 40,000 in 3-7\% tranche etc.).

First we start with the equity tranche where the base correlation equals the implied correlation, then we need to evaluate the base correlation for the two lowest tranches. Taking correlation of 0.4 the present value of the $0-3 \%$ tranche equals 0 and present value of the $3-7 \%$ tranche is negative. Both these tranches' premiums are decreasing in correlation (see Figure 4). Therefore, we run the calculation with a higher value of correlation given market quotes which increases the present value of both tranches. Setting correlation to 0.44 we obtain the present value of the $0-3 \%$ tranche worth USD $+3,200$ and the present value of the $3-7 \%$ tranche worth USD $-3,200$. Therefore 0.44 is the base correlation for the two lowest tranches.

\section{Figure 6}

\section{Base and Implied Correlation for Tranches on 28 February 2009}
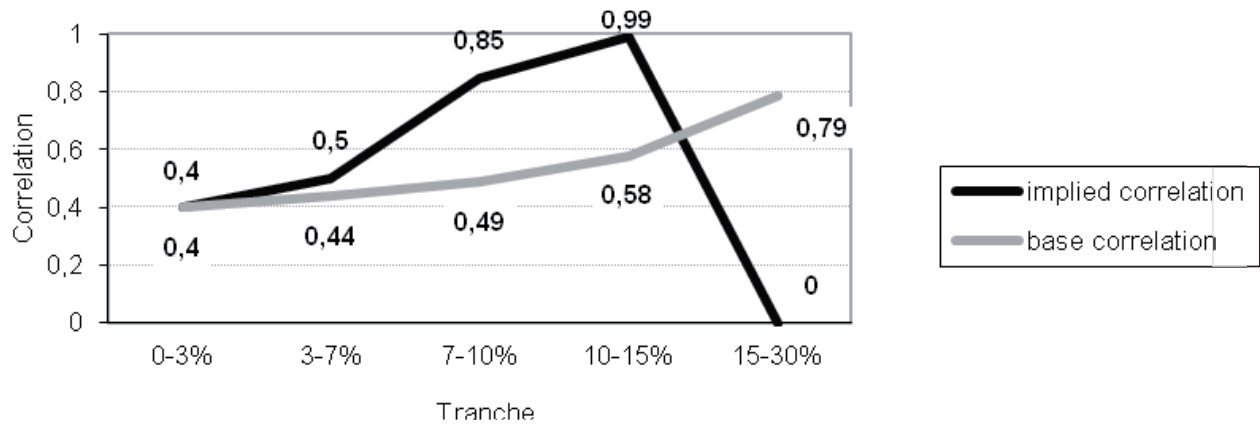

Source: Authors

We continue in this manner to determine the base correlation for all other tranches. The base correlation is by definition monotonically increasing in correlation and according to our calculations it is more stable than the implied correlation, which is in compliance with Hypothesis 2.

\section{Hypothesis 3: Correlation and hazard rate changed between 20 September 2007 and 28 February 2009}

In case of a standard CDO, the most senior tranche (30-100\%) is not sold to protection sellers and is usually retained by the issuer and therefore not included into our calculations. Figure 8 shows the evolution of base correlation during the financial crisis and clearly demonstrates that the base correlation changed in the observed period. That approves the first part of Hypothesis 3. The second part of the hypothesis regarding the hazard rate is discussed in Section 5.2.3. 


\section{Figure 7}

Base Correlation of Tranches on 28 February 2009 and 20 September 2007

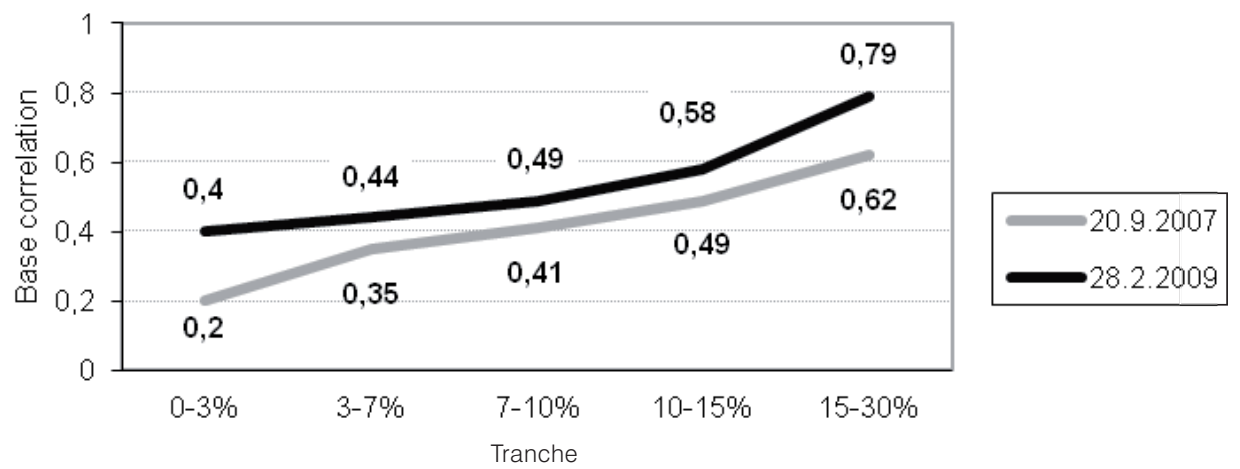

Source: Authors

\subsubsection{Hazard rate and tranche premium evaluation (Hypothesis 4)}

Hypothesis 4: Higher hazard rate increases the premium of all tranches more than proportionally

Hazard rate for an asset is calculated from the credit default swap quote and recovery rate. Higher premium of a $\mathrm{CDO}$ implies to a higher credit risk of an asset. The premium of any CDO tranche based on a pool of assets also increases. Higher recovery rate adverts to lower loss given default and therefore the premium of a CDO tranche would be lower (Figure 8). We assume constant correlation of 0.4 .

Figure 8

Tranche's Premium with Respect to a Hazard Rate on 28 February 2009

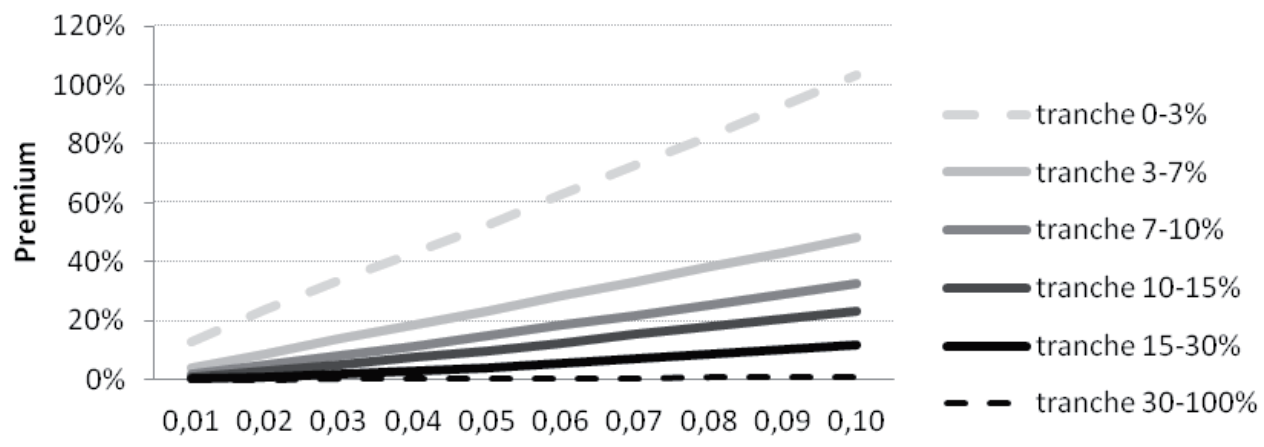

Hazard rate

Source: Authors 
Moreover, by looking at Figure 8 we would see that the higher the seniority of the tranche, the more convex the relation between the premium and hazard rates. The higher the hazard rate, the higher the compensation in form of tranche's premium has to be to offset increased credit risk. Accordingly, the mark-to-market loss on the senior tranche in case of an increase of hazard rate has to be expected higher for higher starting level of the hazard rate. This is in line with Hypothesis 4.

\subsubsection{Loss evaluation (Hypothesis 5)}

Hypothesis 5: There has been a substantial loss on the most senior tranche without a necessity to be hit directly by a default.

We already mentioned that an expressive increase of credit risk during the financial upheaval. The premiums of the tranches often multiplied in the crisis even despite the fact that after each default the index was recalculated. In this part, we will transform the CDX to a CDO, i.e. we will abolish the feature of the new version of the index following each default. The loss after a default can be separated to three parts according to a consequence of: i) increased perception of credit risk; ii) new definition of tranche attachment and detachment point and iii) settlement of the defaulted asset. The first part points to a pure increase of fear on the market. Numerically it is expressed by an increase of hazard rate and correlation between assets. The second part of the loss is numerically expressed by a decrease of a number of underlying assets given fixed volume and decrease of attachment and detachment points' absolute values by the notional of the defaulted assets, both with fixed hazard rate and correlation. The third part of the loss bears only one tranche depending on sequences of the default.

Table 2

Change of a Premium and Loss on a Tranche after 1-3 Defaults and Hazard Rate

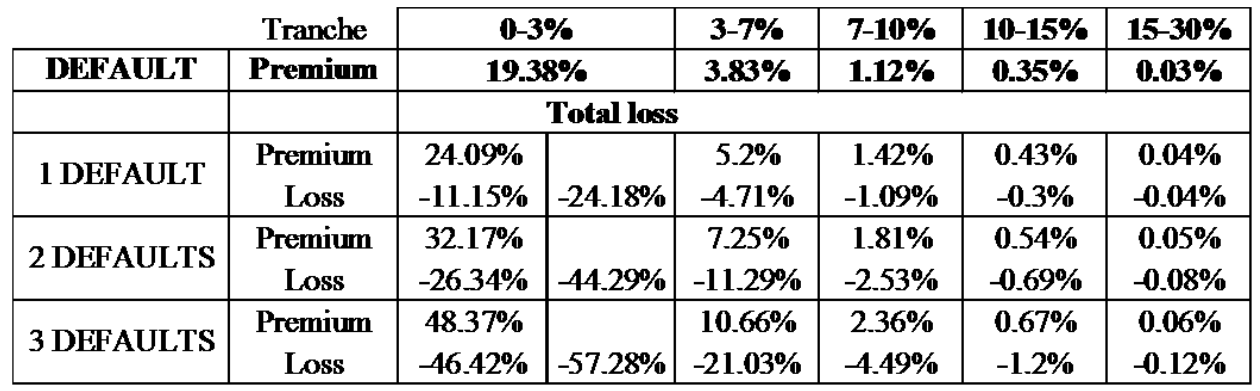

Source: Authors

Table 2 offers an illustration of the second and third part of a loss. Note that the premium for the highest tranche doubles (from $0.03 \%$ with no default to $0.06 \%$ after three defaults) with three defaults even if the change of correlation and hazard rate during time is not included. The total loss including the risk aversion increase and market mode is evaluated in further paragraphs. 
In our calculation we suppose a CDO tranche buyer who entered the CDO contract on 20 September 2007 and hold the CDO until 28 February 2009. This implies that his CDO suffered three defaults during its life. Our task is to evaluate his loss on 28 February 2009 based on the difference between the premium he agreed and the current fair premium based on expected cash flows. First, we evaluate the $\mathrm{CDO}$ as of the issue date. Consequently, we evaluate it on the valuation date with new parameters (Table 3).

Table 3

Changes in Parameters of the Model between 28 February 2009 and 20 September 2007

\begin{tabular}{|l|c|c|}
\hline & 20.9 .2007 & 28.2 .2009 \\
\hline Correlation & 0.32 & 0.44 \\
\hline Hazard rate & 0.01 & 0.07 \\
\hline Number of assets & 125 & 122 \\
\hline Notional invested & USD 100 mil. & USD 97.6 mil. \\
\hline AP and DP & & -2.4 percentage points \\
\hline
\end{tabular}

Note: $\mathrm{AP}=$ attachment point, $\mathrm{DP}=$ attachment point

Source: Authors

The hazard rate was deduced from the credit default swap spreads of the underlying assets based on 0.39 recovery rate and it has increased seven times since autumn 2008. That approves the second part of Hypothesis 3 and points to increased fear on the market. The correlation also increased. It is set as an average base correlation for three lowest tranches (Figure 8). Compared to Table 2 in Table 4 the effect of an increase of correlation and hazard rate is included to determine the total loss of each tranche.

Table 4

Mark-to-Market Loss on a CDO Tranche on 28 February 2009 with USD 10 million Initial Investment

\begin{tabular}{|c|c|c|c|c|c|c|}
\hline & \multicolumn{5}{|c|}{ TRANCHE } \\
\hline & & $0-3 \%$ & $3-7 \%$ & $7-10 \%$ & $10-15 \%$ & $15-30 \%$ \\
\hline 20.9.2007 & Premium & $14.69 \%$ & $4.21 \%$ & $1.89 \%$ & $0.88 \%$ & $0.19 \%$ \\
\hline \multirow{3}{*}{ 28.2.2009 } & Premium & $121.10 \%$ & $46.94 \%$ & $26.52 \%$ & $17.76 \%$ & $8.37 \%$ \\
\hline & $\%$ M-t-M Loss & $-82.12 \%$ & $-71.28 \%$ & $-57.39 \%$ & $-46.13 \%$ & $-26.59 \%$ \\
\hline & M-t-M Loss & 8812000 & 7128000 & 5739000 & 4613000 & 2659000 \\
\hline
\end{tabular}

Source: Authors 
We should note that what we call the mark-to-market loss is in fact the loss based on changed values of expected cash flows (i.e. the loss based on mark-to-market change of entry parameters and the tranches are still valued by the model). The real mark-tomarket loss would have to be derived from the market value of an instrument based on the fair value accounting principle. There are no available market data to a particular $\mathrm{CDO}$ but we can deduce from Figure 2 that this loss would be much higher. In fact we might assume that such CDO contract would have to be terminated before our valuation date. The reason is that we did not fully include other risks such as liquidity risk and market sentiment (despite that these factors are partly included in the hazard rate).

The outcomes of our model using the expected cash flows are alarming. The premium on the most senior tranche increased 44 times in the observed period, while the loss on this tranche amounted $26.50 \%$ of the notional amount. We should mention that these senior tranches usually got the highest possible rating scores indicating poor risk assessment of CDOs from rating agencies. As a consequence, the data confirm Hypothesis 5.

Even though only the equity tranche investors were factually hit by the defaults, all tranches were hit indirectly - in form of mark-to-market losses - regardless of their rating. Although it is improbable that more than 18 defaults occur resulting in a direct hit of the $15-30 \%$ tranche, its mark-to-market loss is high. Even if the investor decided to hold the tranche to maturity, as a financial institution it would have to report a significant loss in its accounting.

\subsection{Four main flaws of the CDO market}

As a consequence of the financial turmoil, financial institutions have suffered from massive writedowns (Figure 3). It is worthwhile to note that majority of these writedowns resulted from only seven credit events (Washington Mutual Inc., Lehman Brothers Holdings Inc., Fannie Mae, Freddie Mac, Glitnir. Kaupthing and Landsbanki). After these credit events numerous downgrades by rating agencies followed. The agencies downgraded the tranches of CDOs with underlying assets issued by any of these seven companies (for example Standard \& Poor's downgraded 791 tranches of CDOs during one week in December 2008). As a result, the companies that held large positions in these CDOs had to be downgraded too (for instance AIG, MBIA or Ambac were downgraded due to CDS hedging their CDO positions losses). Frequently these companies were also included in CDOs and therefore caused further downgrades and mark-to-market losses. Thus the mortgage crisis was no doubt the trigger of the following complex credit crunch. What went wrong that the losses were so high and CDO market collapsed after a couple of defaults?

Standard \& Poors estimated that $3.000 \mathrm{CDO}$ contracts were issued as of October 2008 (Thomson Reuters, 2008), while $75 \%$ of synthetic CDOs sold swaps on Lehman Brothers. Moreover, 376 contracts included Kaupthing, Glitnir or Landsbanki and 1.500 contracts incorporated Washington Mutual and 1.200 contracts encompassed both Fannie Mae and Freddie Mac. In Europe 75\% of all CDO deals contained at least 
one of the 7 defaulted companies. That implies that the CDO market lacked real diversification at that time. Non-diversified CDOs' portfolios, low cohesion of international financial markets together with the spiralling out of control of mark-to-market losses and downgrades resulted in disastrous consequences. We suggest four main weaknesses of the CDO market, their effects and lessons that should be learnt.

First, CDO investors did not undertake a deeper analysis of CDO underlying assets. It should have been alarming that in many cases the issued volume of a bond was much lower than the total volume included in CDO contracts. Rating agencies should have also reflected low diversification and the threat of CDO market breakdown after even a few defaults (due to advanced complexity of the CDO market).

Second, the valuation model comprehension was often incomplete. Neither the basic model introduced in Section 3 was comprehended by the investors as they relied on ratings and did not concern why a bond rated AAA by S\&P yielded less than a CDO tranche with the same rating. The valuation model is a probability model which derives a price of a CDO based on probability of default. The extreme case of multiple credit events is taken into account - it is priced in. Its probability is low but not zero, such that it can happen - and it happened. Moreover, the valuation models are based on future expected cash flows and show the value for investors who hold a CDO to maturity and hence should not be valued on the mark-to-market principle. If an investor buys a senior tranche, after three defaults the chance of being hit is still very low and his cash flow would remain unchanged and therefore the basic idea of the model was correct. However, the model does not take into account mark-to-market losses. This should have been understood by the majority of investors that have to disclose the mark-tomarket value of their assets. Stress tests on changing input parameters - hazard rate and correlation - in combination with credit events should have been run (similar to Tables 2 and 4). Last but not least, the resulting losses based on model quotes can be only considered as the lower bound of losses, because the market quotes tend to overreact in bad times. This complex analysis would lead to a better risk assessment of a $\mathrm{CDO}$ and higher premiums required from a $\mathrm{CDO}$ seller.

Third, the correlation was obviously mispriced in the model. As explained in Section 4 , both the implied and base correlations are derived from CDO market quotes. In the previous paragraph we argued that the tranches were mispriced and therefore neither the correlation value was correct. Only after the market proper valuation of a CDO the actual value of correlation can be derived. Technically, market participants underestimated the possibility of an increase of correlation of the default times and the speed of the contagion.

Finally, the mark-to-market valuation principle according to the US law should be reconsidered. After the mentioned defaults the CDO market froze and the quotes of tranches plummeted. However, all financial institutions still had to value their assets according to these market quotes, in spite of their intention to hold CDOs until maturity. As a consequence, this obligation has induced multiple losses. In October 2008 the Emergency Economic Stabilization Act (often referred to as a bailout of the US 
financial system) was pronounced in the US. Primarily, the Act set apart USD 700 billion for purchase of distressed assets and capital injection of the US banks. Additionally it also allowed in some cases suspending the mark-to-market accounting. Instead the value of a distressed asset can be derived from the expected value of cash flows, i.e. it can be valued according to the model. As discussed in Section 5.2.2, such valuation would cause huge losses after the default and change of input parameters but in a lesser extent compared to the use of distressed market quotes.

\section{Conclusion}

The world CDO market has undoubtedly experienced a serious shock since late 2007 . In this paper we research the main flaws of the CDO market that caused extensive writedowns from CDOs for many financial institutions worldwide. We present the One Factor Model based on a Gaussian Copula and developed a simple valuation program in VBA/MS Excel in which we run simulations to test five hypotheses. Based on the results we discovered four main deficiencies of the CDO market and made our recommendation for their elimination.

Specifically, for our modelling we used the CDX index data from 20 September 2007 until 27 February 2009 the quotes of which we appropriately transformed to CDO quotes. Then we run our valuation with varying entry parameters to show the sensitivities of all tranches. Finally, we compared a model value of a tranche before and during the crisis to value a loss of $\mathrm{CDO}$ investors based on changed expected cash flows. We conclude that this loss constitutes a lower bound of real mark-to-market losses incurred by investors.

The first identified deficiency was an insufficient analysis of underlying assets by both investors and rating agencies. The fact that seven financial institutions that defaulted since September to December 2008 were included in $75 \%$ of all European synthetic CDOs should be alarming. Such a poor diversification has resulted in chain reaction of losses and downgrades of institutions and CDO tranches after these few defaults. Therefore a deeper analysis of diversification effects and quality of underlying assets should be implemented in the future. Low understanding of the valuation model caused the second deficiency. Since the structure and the valuation of a CDO remains quite sophisticated, investors relied on a high rating of senior CDO tranches without understanding the main underlying risks. The model is based on expected cash flows. The possibility of mark-to-market losses of the tranches should have been included in CDO investment decision. Results of stress-testing of tranches would have increased the expected premium payments and would better reflect higher credit risk involved. The third deficiency we found was the fact that also correlation was mispriced. Both implied and base correlations derive from the market quotes which were artificially lowered by improper market optimism. Only after a deep understanding of the CDO valuation model the correlation should have been priced correctly. Also, market participants underestimated the possibility of an increase of correlation. Finally, as we numerically demonstrated, the mark-to-market valuation obligation for financial institu- 
tions should be reviewed and it should be possible to back out of it in cases of a frozen market when risk premiums explode. Accordingly, the expected cash flows valuation should be considered especially if the instrument is held to maturity. Otherwise a next set of writedowns and downgrades may be triggered.

Based on the mentioned recommendations we conclude that the CDO market has a chance to be regenerated but in much smaller volumes compared to the pre-crisis period. Securitization and credit market is needed but the trades have to be done rationally and deliberately which was not the case of past couple of years. The future CDO market would then be more conscious, driven by smarter motives and less extensive.

\section{References}

Amato, J.; Gyntelberg, J. (2005), "CDX Index Tranches and the Pricing of Credit Risk Correlations." BIS Quarterly Review, March 2005.

Asset-Backed Alert (2009), "The Weekly Update on Worldwide Securitization." 14 May 2009. Access from http://www.abalert.com.

Benešová, P.; Teplý, P. (2010), "Main Flaws of The Collateralized Debt Obligation's Valuation before and during The 2008/2009 Global Turmoil." IES FSV Charles University, IES Working Paper $1 / 2010$.

Fabozzi, F. J.; Kothari (2008), V. Introduction to Securitization. Singapore: John Willey \& Sons.

Fabozzi, F. J. (2008), Subprime Mortgage Credit Derivatives. Singapore: John Willey \& Sons.

Gregory, J.; Laurent, J. (2004), "In the Core of Correlation." Risk. Vol. 17, No. 10, pp. 87-91.

Hájek, R.; Mesiar, R. (2008), "On Copulas, Quasicopulas and Fuzzy Logic." Soft Computing 12, pp. 1239-1243.

Hull, J.; White, A. (2004), "Valuation of a CDO and an n-th to Default CDS without Monte Carlo Simulation." Journal of Derivatives. Vol. 12, No. 2, pp. 8-23. Access from http://www.defaultrisk. com/pp_crdrv_14.htm.

IMF (2008), Global Financial Stability Report, Washington: International Monetary Fund.

Kakodkar, A. et al. (2003), Correlation Trading, A New Asset Class Emerges. Credit Derivatives Handbook. New York: Merrill Lynch.

Klement, E. P.; Mesiar, R.; Pap, E. (2005), “Transformation of Copulas.” Kybernetika 41/2005, No. 4, pp. 425-434.

Kybernetika (2008), Special Volume for the Theory of Copulas. Kybernetika 41/2008, No. 6, the whole volume.

Li, D., X. (2000), "On Default Correlation: A Copula Function Approach.” Journal of Fixed Income. 2000, Vol. 9, No. 4, pp. 43-54.

Li, D., X. (1998), "Constructing a Credit Curve, Credit Risk." A Risk Special Report, pp. 40-44.

Markit (2008), Markit iTraxx Europe Indices, Series 10, 2008.

Mejstř́í, M.; Pečená, M.; Teplý, P. (2008), Basic Principles of Banking. Prague: Karolinum Press.

Nelsen, R. B. (2006), An Introduction to Copulas. New York: Springer.

Teplý, P. (2010), The Truth About The 2008-2009 Crisis: A Hard Lesson for The Global Markets. Saarbrücken: VDM Verlag.

Thomson Reuters (2008), Credit News, 22 October 2008.

Wang, D.; Rachev, S. T.; Fabozzi, F. J. (2006), "Pricing Tranches of a CDO and a CDS Index: Recent Advances and Future Research." Working Paper. 